\title{
CARTA DE LOS DERECHOS FUNDAMENTALES DE LA UNIÓN EUROPEA (2000)
}

\section{PREÁMBULO}

Los pueblos de Europa, al crear entre sí una unión cada vez más estrecha, han decidido compartir un porvenir pacífico basado en valores comunes.

Consciente de su patrimonio espiritual y moral, la Unión está fundada sobre los valores indivisibles y universales de la dignidad humana, la libertad, la igualdad y la solidaridad, y se basa en los principios de la democracia y del Estado de Derecho. Al instituir la ciudadanía de la Unión y crear un espacio de libertad, seguridad y justicia, sitúa a la persona en el centro de su actuación.

La Unión contribuye a la preservación y al fomento de estos valores comunes dentro del respeto de la diversidad de culturas y tradiciones de los pueblos de Europa, así como de la identidad nacional de los Estados miembros y de la organización de sus poderes públicos en el plano nacional, regional y local; trata de fomentar un desarrollo equilibrado y sostenible y garantiza la libre circulación de personas, bienes, servicios y capitales, así como la libertad de establecimiento.

Para ello es necesario, dotándolos de mayor presencia en una Carta, reforzar la protección de los derechos fundamentales a tenor de la evolución de la sociedad, del progreso social y de los avances científicos y tecnológicos.

La presente Carta reafirma, respetando las competencias y misiones de la Comunidad y de la Unión, así como el principio de subsidiariedad, los derechos reconocidos especialmente por las tradiciones constitucionales y las obligaciones internacionales comunes de los Estados miembros, el Tratado de la Unión Europea y los Tratados comunitarios, el Convenio Europeo para la Protección de los Derechos Humanos y de las Libertades Fundamentales, las Cartas Sociales adoptadas por la Comunidad y por el Consejo de Europa, así como por la jurisprudencia del Tribunal de Justicia de las Comunidades Europeas y del Tribunal Europeo de Derechos Humanos.

El disfrute de tales derechos origina responsabilidades y deberes tanto respecto de los demás como de la comunidad humana y de las futuras generaciones.

En consecuencia, la Unión reconoce los derechos, libertades y principios enunciados a continuación.

\section{CAPÍTULO I: DIGNIDAD}

\section{ARTÍ́CULO 1. DigNIDAD HUMANA}

La dignidad humana es inviolable. Será respetada y protegida.

\section{ARTÍ́CULO 2. DERECHO A LA VIDA}

1. Toda persona tiene derecho a la vida.

2. Nadie podrá ser condenado a la pena de muerte ni ejecutado.

\section{ARTíCUlO 3. DERECHO A LA INTEGRIDAD DE LA PERSONA}

1. Toda persona tiene derecho a su integridad física y psíquica.

2. En el marco de la medicina y la biología se respetarán en particular:

- el consentimiento libre e informado de la persona de que se trate, de acuerdo con las modalidades establecidas en la ley, 
- la prohibición de las prácticas eugenésicas, y en particular las que tienen por finalidad la selección de las personas,

- la prohibición de que el cuerpo humano o partes del mismo en cuanto tales se conviertan en objeto de lucro,

- la prohibición de la clonación reproductora de seres humanos.

\section{ARTíCULO 4. PROHIBICIÓN DE LA TORTURA Y DE LAS PENAS O LOS TRATOS INHUMANOS O DEGRADANTES}

Nadie podrá ser sometido a tortura ni a penas o tratos inhumanos o degradantes.

\section{ARTÍCULO 5. PROHIBICIÓN DE LA ESCLAVITUD Y DEL TRABAJO FORZADO}

1. Nadie podrá ser sometido a esclavitud o servidumbre.

2. Nadie podrá ser constreñido a realizar un trabajo forzado u obligatorio.

3. Se prohíbe la trata de seres humanos.

\section{CAPÍTULO II: LIBERTADES}

\section{ARTíCULO 6. DERECHO A LA LIBERTAD YA LA SEGURIDAD}

Toda persona tiene derecho a la libertad ya la seguridad.

\section{ARTÍCULO 7. RESPETO DE LA VIDA PRIVADA Y FAMILIAR}

Toda persona tiene derecho al respeto de su vida privada y familiar, de su domicilio y de sus comunicaciones.

\section{ARTíCULO 8. PROTECCIÓN DE DATOS DE CARÁCTER PERSONAL}

1. Toda persona tiene derecho a la protección de los datos de carácter personal que la conciernan.

2. Estos datos se tratarán de modo leal, para fines concretos y sobre la base del consentimiento de la persona afectada o en virtud de otro fundamento legítimo previsto por la ley. Toda persona tiene derecho a acceder a los datos recogidos que la conciernan ya su rectificación.

3. El respeto de estas normas quedará sujeto al control de una autoridad independiente.

\section{ARTÍCULO 9. DERECHO A CONTRAER MATRIMONIO Y DERECHO A FUNDAR UNA FAMILIA}

Se garantizan el derecho a contraer matrimonio y el derecho a fundar una familia según las leyes nacionales que regulen su ejercicio.

\section{ARTÍCULO 10. LIBERTAD DE PENSAMIENTO, DE CONCIENCIA Y DE RELIGIÓN}

1. Toda persona tiene derecho a la libertad de pensamiento, de conciencia y de religión. Este derecho implica la libertad de cambiar de religión o de convicciones, así como la libertad de manifestar su religión o sus convicciones individual o colectivamente, en público o en privado, a través del culto, la enseñanza, las prácticas y la observancia de los ritos.

2. Se reconoce el derecho a la objeción de conciencia de acuerdo con las leyes nacionales que regulen su ejercicio.

3. Las nacionales de terceros países que estén autorizados a trabajar en el territorio de los Estados miembros tiene derecho a unas condiciones laborales equivalentes a aquellas que disfrutan los ciudadanos de la Unión.

\section{ARTÍCULO 11. LIBERTAD DE EXPRESIÓN Y DE INFORMACIÓN}

1. Toda persona tiene derecho a la libertad de expresión. Este derecho comprende la libertad de opinión y la libertad de recibir o de comunicar informaciones o ideas sin que pueda haber injerencia de autoridades públicas y sin consideración de fronteras.

2. Se respetan la libertad de los medios de comunicación y su pluralismo. 


\section{ARTÍCULO 12. LIBERTAD DE REUNIÓN Y DE ASOCIACIÓN}

1. Toda persona tiene derecho a la libertad de reunión pacífica ya la libertad de asociación en todos los niveles, especialmente en los ámbitos político, sindical y cívico, lo que implica el derecho de toda persona a fundar con otras sindicatos ya afiliarse a los mismos para la defensa de sus intereses.

2. Los partidos políticos a escala de la Unión contribuyen a expresar la voluntad política de los ciudadanos de la Unión.

\section{ARTÍCULO 13. LIBERTAD DE LAS ARTES Y DE LAS CIENCIAS}

Las artes y la investigación científica son libres. Se respeta la libertad de cátedra.

\section{ARTíCULO 14. DERECHO A LA EDUCACIÓN}

1. Toda persona tiene derecho a la educación y al acceso a la formación profesional y permanente.

2. Este derecho incluye la facultad de recibir gratuitamente la enseñanza obligatoria.

3. Se respetan, de acuerdo con las leyes nacionales que regulen su ejercicio, la libertad de creación de centros docentes dentro del respeto a los principios democráticos, así como el derecho de los padres a garantizar la educación y la enseñanza de sus hijos conforme a sus convicciones religiosas, filosóficas y pedagógicas.

\section{ARTÍCULO 15. LIBERTAD PROFESIONAL Y DERECHO A TRABAJAR}

1. Toda persona tiene derecho a trabajar ya ejercer una profesión libremente elegida o aceptada.

2. Todo ciudadano de la Unión tiene la libertad de buscar un empleo, de trabajar, de establecerse o de prestar servicios en cualquier Estado miembro.

3. Los nacionales de terceros países que estén autorizados a trabajar en el territorio de los Estados miembros tienen derecho a unas condiciones laborales equivalentes a aquellas que disfrutan los ciudadanos de la Unión.

\section{ARTICULO 16. LIBERTAD DE EMPRESA}

Se reconoce la libertad de empresa de conformidad con el Derecho comunitario y con las legislaciones y prácticas nacionales.

\section{ARTÍ́CULO 17. DERECHO A LA PROPIEDAD}

1. Toda persona tiene derecho a disfrutar de la propiedad de sus bienes adquiridos legalmente, a usarlos, a disponer de ellos ya legarlos. Nadie puede ser privado de su propiedad más que por causa de utilidad pública, en los casos y condiciones previstos en la ley ya cambio, en un tiempo razonable, de una justa indemnización por su pérdida. El uso de los bienes podrá regularse por ley en la medida que resulte necesario para el interés general.

2. Se protege la propiedad intelectual.

\section{ARTiCUlo 18. DERECHO DE ASILO}

Se garantiza el derecho de asilo dentro del respeto de las normas de la Convención de Ginebra de 28 de julio de 1951 y del Protocolo de 31 de enero de 1967 sobre el Estatuto de los Refugiados y de conformidad con el Tratado constitutivo de la Comunidad Europea.

\section{ARTíCULO 19. PROTECCIÓN EN CASO DE DEVOLUCIÓN, EXPULSIÓN Y EXTRADICIÓN}

1. Se prohíben las expulsiones colectivas.

2. Nadie podrá ser devuelto, expulsado o extraditado aun Estado en el que corra un grave riesgo de ser sometido ala pena de muerte, a tortura o a otras penas o tratos inhumanos o degradantes. 


\section{CAPÍTULO III: IGUALDAD}

ARTíCULO 20. IGUALDAD ANTE LA LEY

Todas las personas son iguales ante la ley.

\section{ARTÍ́CULO 21. NO DISCRIMINACIÓN}

1. Se prohíbe toda discriminación, y en particular la ejercida por razón de sexo, raza, color, orígenes étnicos o sociales, características gen éticas, lengua, religión o convicciones, opiniones políticas o de cualquier otro tipo, pertenencia a una minoría nacional, patrimonio, nacimiento, discapacidad, edad u orientación sexual.

2. Se prohíbe toda discriminación por razón de nacionalidad en el ámbito de aplicación del Tratado constitutivo de la Comunidad Europea y del Tratado de la Unión Europea y sin perjuicio de las disposiciones particulares de dichos Tratados.

\section{ARTíCULO 22. DIVERSIDAD CULTURAL, RELIGIOSA Y LINGÜÍSTICA}

La Unión respeta la diversidad cultural, religiosa y lingüística.

\section{ARTÍCULO 23. IGUALDAD ENTRE HOMBRES Y MUJERES}

La igualdad entre hombres y mujeres será garantizada en todos los ámbitos, inclusive en materia de empleo, trabajo y retribución.

El principio de igualdad no impide el mantenimiento o la adopción de medidas que ofrezcan ventajas concretas en favor del sexo menos representado.

\section{ARTÍCULO 24. DERECHOS DEL MENOR}

1. Los menores tienen derecho a la protección ya los cuidados necesarios para su bienestar. Podrán expresar su opinión libremente. Ésta será tenida en cuenta en relación con los asuntos que les afecten, en función de su edad y de su madurez.

2. En todos los actos relativos a los menores llevados a cabo por autoridades públicas o instituciones privadas, el interés superior del menor constituirá una consideración primordial.

3. Todo menor tiene derecho a mantener de forma periódica relaciones personas y contactos directos con su padre y con su madre, salvo si son contrarios a sus intereses.

\section{ARTíCULO 25. DERECHOS DE LAS PERSONAS MAYORES}

La Unión reconoce y respeta el derecho de las personas mayores a llevar una vida digna e independiente ya participar en la vida social y cultural.

\section{ARTÍCULO 26. INTEGRACIÓN DE LAS PERSONAS DISCAPACITADAS}

La Unión reconoce y respeta el derecho de las personas discapacitadas a beneficiarse de medidas que garanticen su autonomía, su integración social y profesional y su participación en la vida de la comunidad.

\section{CAPÍTULO IV: SOLIDARIDAD}

\section{ARTíCULO 27. DERECHO A LA INFORMACIÓN Y CONSULTA DE LOS TRABAJADORES EN LA EMPRESA}

Se deberá garantizar a los trabajadores o a sus representantes, en los niveles adecuados, la información y consulta con suficiente antelación en los casos y condiciones previstos en el Derecho comunitario y en las legislaciones y prácticas nacionales. 


\section{ARTíCULO 28. DERECHO DE NEGOCIACIÓN Y DE ACCIÓN COLECTIVA}

Los trabajadores y los empresarios, o sus organizaciones respectivas, de conformidad con el Derecho comunitario y con las legislaciones y prácticas nacionales, tienen derecho a negociar y celebrar convenios colectivos, en los niveles adecuados, ya emprender, en caso de conflicto de intereses, acciones colectivas para la defensa de sus intereses, incluida la huelga.

\section{ARTí́CUlO 29. DERECHO DE ACCESO A LOS SERVICIOS DE COLOCACIÓN}

Toda persona tiene derecho a acceder aun servicio gratuito de colocación.

\section{ARTíCULO 30. PROTECCIÓN EN CASO DE DESPIDO INJUSTIFICADO}

Todo trabajador tiene derecho a una protección en caso de despido injustificado, de conformidad con el Derecho comunitario y con las legislaciones y prácticas nacionales.

\section{ARTÍCULO 31. CONDICIONES DE TRABAJO JUSTAS Y EQUITATIVAS}

1. Todo trabajador tiene derecho a trabajar en condiciones que respeten su salud, su seguridad y su dignidad.

2. Todo trabajador tiene derecho a la limitación de la duración máxima del trabajo ya períodos de descanso diarios y semanales, así como aun período de vacaciones anuales retribuidas.

\section{ARTíCULO 32. PROHIBICIÓN DEL TRABAJO INFANTIL Y PROTECCIÓN DE LOS JÓVENES EN EL TRABAJO}

Se prohíbe el trabajo infantil. La edad mínima de admisión al trabajo no podrá ser inferior a la edad en que concluye la escolaridad obligatoria, sin perjuicio de disposiciones más favorables para los jóvenes y salvo excepciones limitadas.

Los jóvenes admitidos a trabajar deben disponer de condiciones de trabajo adaptadas a su edad y estar protegidos contra la explotación económica o contra cualquier trabajo que pueda ser perjudicial para su seguridad, su salud, su desarrollo físico, psíquico, moral o social, o que pueda poner en peligro su educación.

\section{ARTÍCULO 33. VIDA FAMILIAR Y VIDA PROFESIONAL}

1. Se garantiza la protección de la familia en los planos jurídicos, económico y social.

2. Con el fin de poder conciliar vida familiar y vida profesional, toda persona tiene derecho a ser protegida contra cualquier despido por una causa relacionada con la maternidad, así como el derecho a un permiso pagado por maternidad y a un permiso parental con motivo del nacimiento o de la adopción de un niño.

\section{ARTÍCULO 34. SEGURIDAD SOCIAL Y AYUDA SOCIAL}

1. La Unión reconoce y respeta el derecho de acceso a las prestaciones de seguridad social ya los servicios sociales que garantizan una protección en casos como la maternidad, la enfermedad, los accidentes laborales, la dependencia o la vejez, así como en caso de pérdida de empleo, según las modalidades establecidas por el Derecho comunitario y las legislaciones y prácticas nacionales.

2. Toda persona que resida y se desplace legalmente dentro de la Unión tiene derecho a las prestaciones de seguridad social ya las ventajas sociales con arreglo al Derecho comunitario ya las legislaciones y prácticas nacionales.

3. Con el fin de combatir la exclusión social y la pobreza, la Unión reconoce y respeta el derecho a una ayuda social ya una ayuda de vivienda para garantizar una existencia digna a todos aquellos que no dispongan de recursos suficientes, según las modalidades establecidas por el Derecho comunitario y las legislaciones y prácticas nacionales. 


\section{ARTíCULO 35. PROTECCIÓN DE LA SALUD}

Toda persona tiene derecho a la prevención sanitaria ya beneficiarse de la atención sanitaria en las condiciones establecidas por las legislaciones y prácticas nacionales. Al definirse y ejecutarse todas las políticas y acciones de la Unión se garantizará un alto nivel de protección de la salud humana.

\section{ARTÍCULO 36. ACCESO A LOS SERVICIOS DE INTERÉS ECONÓMICO GENERAL}

La Unión reconoce y respeta el acceso a los servicios de interés económico general, tal como disponen las legislaciones y prácticas nacionales, de conformidad con el Tratado constitutivo de la Comunidad Europea, con el fin de promover la cohesión social y territorial de la Unión.

\section{ARTíCULO 37. PROTECCIÓN DEL MEDIO AMBIENTE}

Las políticas de la Unión integrarán y garantizarán con arreglo al principio de desarrollo sostenible un alto nivel de protección del medio ambiente y la mejora de su calidad.

\section{ARTÍ́CULO 38. PROTECCIÓN DE LOS CONSUMIDORES}

Las políticas de la Unión garantizarán un alto nivel de protección de los consumidores.

\section{CAPÍTULO V: CIUDADANÍA}

\section{ARTíCUlO 39. DeRECHO A SER ELECTOR Y ELEGIBLE EN LAS ELECCIONES AL PARLAMENTO EUROPEO}

1. Todo ciudadano de la Unión tiene derecho a ser elector y elegible en las elecciones al Parlamento Europeo en el Estado miembro en que resida, en las mismas condiciones que los nacionales de dicho Estado.

2. Los diputados del Parlamento Europeo serán elegidos por sufragio universal libre, directo y secreto.

\section{ARTÍ́CULO 40. DERECHO A SER ELECTOR Y ELEGIBLE EN LAS ELECCIONES MUNICIPALES}

Todo ciudadano de la Unión tiene derecho a ser elector y elegible en las elecciones municipales del Estado miembro en que resida, en las mismas condiciones que los nacionales de dicho Estado.

\section{ARTíCULO 41. DERECHO A UNA BUENA ADMINISTRACIÓN}

1. Toda persona tiene derecho a que las instituciones y órganos de la Unión traten sus asuntos imparcial y equitativamente y dentro de un plazo razonable.

2. Este derecho incluye en particular:

- el derecho de toda persona a ser oída antes de que se tome en contra suya una medida individual que le afecte desfavorablemente,

- el derecho de toda persona a acceder al expediente que le afecte, dentro del respeto de los intereses legítimos de la confidencialidad y del secreto profesional y comercial,

- la obligación que incumbe a la administración de motivar sus decisiones.

3. Toda persona tiene derecho ala reparación por la Comunidad de los daños causados por sus instituciones o sus agentes en el ejercicio de sus funciones, de conformidad con los principios generales comunes a los Derechos de los Estados miembros.

4. Toda persona podrá dirigirse a las instituciones de la Unión en una de las lenguas de los Tratados y deberá recibir una contestación en esa misma lengua.

\section{ARTí́cUlo 42. DERECHO DE ACCESO A LOS DOCUMENTOS}

Todo ciudadano de la Unión o toda persona física o jurídica que resida o tenga su domicilio social en un Estado miembro tiene derecho a acceder a los documentos del Parlamento Europeo, del Consejo y de la Comisión. 


\section{Artículo 43. El Defensor DEl Pueblo}

Todo ciudadano de la Unión o toda persona física o jurídica que resida o tenga su domicilio social en un Estado miembro tiene derecho a someter al Defensor del Pueblo de la Unión los casos de mala administración en la acción de las instituciones u órganos comunitarios, con exclusión del Tribunal de Justicia y del Tribunal de Primera Instancia en el ejercicio de sus funciones jurisdiccionales.

\section{ARTÍCULO 44. DERECHO DE PETICIÓN}

Todo ciudadano de la Unión o toda persona física o jurídica que resida o tenga su domicilio social en un Estado miembro tiene el derecho de petición ante el Parlamento Europeo.

\section{ARTÍCULO 45. LIBERTAD DE CIRCULACIÓN Y DE RESIDENCIA}

1. Todo ciudadano de la Unión tiene derecho a circular y residir libremente en el territorio de los Estados miembros.

2. De conformidad con lo dispuesto en el Tratado constitutivo de la Comunidad Europea, se podrá conceder libertad de circulación y de residencia a los nacionales de terceros países que residan legal- mente en el territorio de un Estado miembro.

\section{ARTíCULO 46. PROTECCIÓN DIPLOMÁTICA Y CONSULAR}

Todo ciudadano de la Unión podrá acogerse, en el territorio de un tercer país en el que no esté representado el Estado miembro del que sea nacional, a la protección de las autoridades diplomáticas y consulares de cualquier Estado miembro, en las mismas condiciones que los nacionales de este Estado.

\section{CAPÍTULO VI: JUSTICIA}

\section{ARTÍCULO 47. DERECHO A LA TUTELA JUDICIAL EFECTIVA YA UN JUEZ IMPARCIAL}

Toda persona cuyos derechos y libertades garantizados por el Derecho de la Unión hayan sido violados tiene derecho a la tutela judicial efectiva respetando las condiciones establecidas en el presente artículo.

Toda persona tiene derecho a que su causa sea oída equitativa y públicamente y dentro de un plazo razonable por un juez independiente e imparcial, establecido previamente por la ley. Toda persona podrá hacerse aconsejar, defender y representar.

Se prestará asistencia jurídica gratuita a quienes no dispongan de recursos suficientes siempre y cuando dicha asistencia sea necesaria para garantizar la efectividad del acceso a la justicia.

\section{ARTÍCULO 48. PRESUNCIÓN DE INOCENCIA Y DERECHOS DE LA DEFENSA}

1. Todo acusado se presume inocente hasta que su culpabilidad haya sido legalmente declarada.

2. Se garantiza a todo acusado el respeto de los derechos de la defensa.

\section{ARTíCULO 49. PRINCIPIOS DE LEGALIDAD Y DE PROPORCIONALIDAD DE LOS DELITOS Y LAS PENAS}

1. Nadie podrá ser condenado por una acción o una omisión que, en el momento en que haya sido cometida, no constituya una infracción según el Derecho nacional o el Derecho internacional. Igual- mente no podrá ser impuesta una pena más grave que la aplicable en el momento en que la infracción haya sido cometida. $\mathrm{Si}$, con posterioridad a esta infracción, la ley dispone una pena más leve, deberá ser aplicada ésta.

2. El presente artículo no impedirá el juicio y el castigo de una persona culpable de una acción o una omisión que, en el momento de su comisión, fuera constitutiva de delito según los principios generales reconocidos por el conjunto de las naciones. 
3. La intensidad de las penas no deberá ser des proporcionada en relación con la infracción.

ARTí́culo 50. DERECHO ANO SER ACUSADO O CONDENAdO PENALMENTE DOS VECES POR EL MiSMO DELITO

Nadie podrá ser acusado o condenado penalmente por una infracción respecto de la cual ya haya sido absuelto o condenado en la Unión mediante sentencia penal firme conforme a la ley.

\section{CAPÍTULO VII: DISPOSICIONES GENERALES}

\section{ARTíCULO 51. ÁMBITO DE APLICACIÓN}

1. Las disposiciones de la presente Carta están dirigidas a las instituciones y órganos de la Unión, respetando el principio de subsidiariedad, así como a los Estados miembros únicamente cuando apliquen el Derecho de la Unión. Por consiguiente, éstos respetarán los derechos, observarán los principios y promoverán su aplicación, con arreglo a sus respectivas competencias.

2. La presente Carta no crea ninguna competencia ni ninguna misión nuevas para la Comunidad ni para la Unión y no modifica las competencias y misiones definidas por los Tratados.

\section{ARTíCUlO 52. AlCANCE DE LOS DERECHOS GARANTIZADOS}

1. Cualquier limitación del ejercicio de los derechos y libertades reconocidos por la presente Carta deberá ser establecida por la ley y respetar el contenido esencial de dichos derechos y libertades. Sólo se podrán introducir limitaciones, respetando el principio de proporcionalidad, cuando sean necesarias y respondan efectivamente a objetivos de interés general reconocidos por la Unión o a la necesidad de protección de los derechos y libertades de los demás.

2. Los derechos reconocidos por la presente Carta que tienen su fundamento en los Tratados comunitarios o en el Tratado de la Unión Europea se ejercerán en las condiciones y dentro de los límites determinados por éstos.

3. En la medida en que la presente Carta contenga derechos que correspondan a derechos garantizados por el Convenio Europeo para la Protección de los Derechos Humanos y de las Libertades Fundamentales, su sentido y alcance serán iguales a los que les confiere dicho Convenio. Esta disposición no impide que el Derecho de la Unión conceda una protección más extensa.

\section{ARTÍCULO 53. NiVEL DE PROTECCIÓN}

Ninguna de las disposiciones de la presente Carta podrá interpretarse como limitativa o lesiva de los derechos humanos y libertades fundamentales reconocidos, en su respectivo ámbito de aplicación, por el Derecho de la Unión, el Derecho internacional y los convenios internacionales de los que son parte la Unión, la Comunidad o los Estados miembros, y en particular el Convenio Europeo para la Protección de los Derechos Humanos y de las Libertades Fundamentales, así como por las constituciones de los Estados miembros.

\section{ARTÍCULO 54. PROHIBICIÓN DEL TRABAJO INFANTIL Y PROTECCIÓN DE LOS JÓVENES EN EL TRABAJO}

Ninguna de las disposiciones de la presente Carta podrá ser interpretada en el sentido de que implique un derecho cualquiera a dedicarse a una actividad o a realizar un acto tendente a la destrucción de los derechos o libertades reconocidos en la presente Carta o a limitaciones más amplias de estos derechos y libertades que las previstas en la presente Carta. 